\title{
0135 COMMUNITY SAFETY FROM HAZARDOUS INDUSTRY AT RURAL AREA IN THAILAND
}

W Karnjanakantorn* Correspondence: Bangkok Hospital Medical Center, 54 SOI Wachiratumsatit49 sukhumvit101/1 Bangjak Prakanong Bangkok, 10260, Thailand

10.1136/ip.2010.029215.135

Background There are many industrial factories in developing country, for example, Thailand. The industrial waste has become a crucial problem.

Aim To study the effect of hazardous, non-hazardous landfill that cause health symptoms and use Geographic Information System to mapping the data.

Methods A cross-sectional survey was conducted during 2007 among sampling four districts total 200 households and Geographic Information System. A total of 200 people participated in the study (44 males, 156 females)compare with 165 employees. Results showed that average age was $46.6+15$ years old. 3117 years live in this province, $92 \%$ work near their house, for example, farmer. The report of smell odour was 170 households (85\%), 90\% first time in 2005. Type of odour was decay $28.8 \%$, irritant $21.8 \%$. There were 138 people $(81.2 \%)$ had symptoms, for example, eye/nose-irritant, headache, dizziness and $20 \%$ went to see the doctor. The most common diagnosis was allergic rhinitis $45 \%$ and 138 households $(82.8 \%)$ consume water from rain, surface water, groundwater. We use GIS to identify the household that had odour problem. We found the households near the landfill (factory 1) had odour problem more than the sugar factory (factory 2). For the periodic examination of employees, we found all employees were healthy. In conclusion, this study shows that landfill is necessary and has less health effect of their employees but we need to monitor and surveillance quality of life in the community. 